КАРА Ж. Ю., КРУТЕЛЕВА Л. Ю.

ОСОБЕННОСТИ СМЫСЛОЖИЗНЕННЫХ И ЦЕННОСТНЫХ ОРИЕНТАЦИЙ МОЛОДЕЖИ...

Российский психологИЧЕСкий жУРнАл, 2019, Т. 16, № 4, 34-41. doi: 10.21702/rpj.2019.4.3

\title{
Особенности смысложизненных и ценностных ориентаций молодежи в период формирования семейных отношений
}

\author{
Жанна Ю. Кара*, Людмила Ю. Крутелева \\ Южный федеральный университет, г. Ростов-на-Дону, Российская Федерация \\ *E-mail: kara j@mail.ru,zykara@sfedu.ru \\ ORCID ID: https://orcid.org/0000-0002-6987-2531, https://orcid.org/0000-0003-3061-943X
}

\begin{abstract}
Аннотация
Введение. В статье рассматриваются ценности и смыслы молодежи, находящейся в процессе фрормирования семейных отношений. Актуальность исслеАования связана с интересом К взаимоотношению молоАЫх АЮАей, К пониманию и выстраиванию собственной Аичностной, жизненной траектории. Цель исслеАования - изучить ценностно-смысловые особенности мо^олежи, находящейся в браке и находящейся в поиске партнера. В исслеАовании приняли участие 61 человек в возрасте 18-35 лет. Авторами рассмотрены в сравнении ценностно-смыс^овые особенности мололежи, находящейся в браке и находящейся в поиске партнера.

Метолы. Применялись сравнительный анализ и обобщение теоретических положений; также были использованы Аиагностические методики: «Методика исслеАования системы жизненных смыслов», «Ценностный опросник Шварца», «Опросник самоотношения»; методы

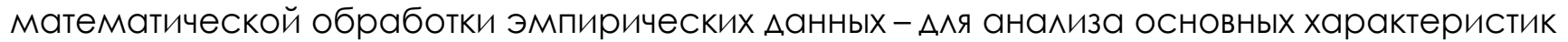
распределения применялись описательная статистика и U-критерий Манна -Уитни.

Результаты и их обсужАение. Выявлено преАпочтение жизненных смыслов в группе молодых ^ЮАей, находящихся в поиске партнера, направленных на: поиск смысла собственной жизни, экзистенциальное осмысление собственного бытия, своего места в обществе, саморазвитие, самореализацию, активное взаимодействие с Аругими ^юАьми. А^я мололежи, находящейся в браке, неактуальна ценность «саморазвитие», что, по мнению авторов, может иметь влияние на целостность семьи. Значимые ценности Аля молодежи, находящейся в браке: ^ичная безопасность, защита от внешних условий, тенАенция к Аостижениям в Аичной и продеессиональной области; важные Аля молодежи, находящейся в поиске партнера, - ценности Аостижения как развитие человека, самостоятельность, как принятие ответственности на себя за свою жизнь.

Приводятся выявленные, статистически значимые взаимосвязи ценностей и смыслов молоАежи в периол формирования семейных отношений. Новизна исслеАования заключается в выявлении и описании жизненных смыслов, ценностей современной российской молоАежи, находящейся в браке и находящейся в поиске партнера.
\end{abstract}

\section{КАючевые слова}

ценности, ценностные ориентации, жизненные смыслы, смыслы, ценностная сорера, смысловая сорера, мололежь, потребности человека, семейные отношения, партнерство 
КАРА Ж. Ю., КРУТЕЛЕВА Л. Ю.

ОСОБЕННОСТИ СМЫСЛОЖИЗНЕННЫХ И ЦЕННОСТНЫХ ОРИЕНТАЦИЙ МОЛОДЕЖИ...

Российский псИХологИЧЕСкий ЖУРнАл, 2019, Т. 16, № 4, 34-41. doi: 10.21702/rpj.2019.4.3

ОБЩАЯ ПСИХОЛОГИЯ, ПСИХОЛОГИЯ ЛИЧНОСТИ, ИСТОРИЯ ПСИХОЛОГИИ

\section{Основные положения}

> состав веАущих ценностей отличается у мололежи, находящейся в браке (безопасность, Аостижения, геАонизм) и находящейся в поиске партнера (Аостижения, самостоятельность, коморортность);

$\checkmark$ жизненные смыслы отличаются у молодежи, находящейся в браке (коммуникативные) и находящейся в поиске партнера (экзистенциальные, гедонистические, самореализация); $\checkmark$ в состав жизненных смыслов и ценностей у молодежи, находящейся в браке и находящейся в поиске партнера, входят: «безопасносты), «Аостижения», «геАОнизм», «самостоятельность», «комфрортность», «стимуляция», «самореализация», «экзистенциальные», «коммуникативные», «семейные».

\section{Для цитирования}

Кара, Ж. Ю. и Крутелёва, Л. Ю. (2019). Особенности смысложизненных и ценностных ориентаций молодежи в период формирования семейных отношений. Российский психологический журнал, 16(4), 34-41. doi: 10.21702/rpj.2019.4.3

Дата получения рукописи: 29.11.2019 Дата окончания рецензирования: 20.01.2020 Дата принятия к публикации: 24.01.2020

\section{Введение}

Современная эпоха характеризуется постоянной трансформацией: социальной, политической, экономической. Человек живет в условиях неопределенности разных сфер жизни, требований принятия быстрых решений, увеличения конкурентной способности, адаптации к современным реалиям. Коренным образом изменились представления об успехе, успешном человеке, о способах достижения успеха, о личной жизни, о ближайшем окружении и, соответственно, трансформировались ценности и смыслы каждого человека. Становится очевидным кризис духовных и нравственных ценностей общества. И молодежь демонстрирует происходящие процессы переоценки и трансформации ценностей и смыслов в российском обществе, в поиске собственного места в мире, в спутнике жизни. В психологии смыслы и ценности определяются как личностные конструкты и основополагающие факторы, детерминирующие выбор жизненного пути человека.

Понятие ценностей и смыслов в психологической науке исследуется давно. За это время накопилось множество различных точек зрения по этой проблематике: психологических, философских, биологических и социально-экономических. В то же время, несмотря на появляющиеся новые исследовательские данные, отметим актуальность траекторий, заданных Узнадзе (1961), который ввел термин «установка», Рубинштейном (2019), оперирующим понятием «динамическая тенденция личности», А. Н. Леонтьевым (1971), Д. А. Леонтьевым (Леонтьев, 2007; Леонтьев, Тараненко и Калашникова, 2017), использующим формулировку «жизненные смыслы». Расширяют исследуемую область смыслов: выбор человеком разнородных ценностей, становящихся затем неоптимальным смыслом жизни (Карпинский, 2017); смысложизненные ориентации личности, определяющие структуру и содержание концепции личности и формирующие далее смысложизненные стратегии личности, характеризующиеся личностным и профессиональным становлением в личной, семейной, профессиональной жизни (Кара 
КАРА Ж. Ю., КРУТЕЛЕВА Л. Ю.

ОСОБЕННОСТИ СМЫСЛОЖИЗНЕННЫХ И ЦЕННОСТНЫХ ОРИЕНТАЦИЙ МОЛОДЕЖИ...

Российский психологический жУРнАл, 2019, Т. 16, № 4, 34-41. doi: 10.21702/rpj.2019.4.3

ОБЩАЯ ПСИХОЛОГИЯ, ПСИХОЛОГИЯ ЛИЧНОСТИ, ИСТОРИЯ ПСИХОЛОГИИ

и Крутелёва, 2012; Кара и Касьянова, 2017; Сухарева и Филиппова, 2018); рассмотрение смыслообразующих стратегий - они выступают как способ формирования личностных смыслов и впоследствии выстраивают картину целостности личности, включающую в себя разные области (личную, семейную, профессиональную (Абакумова, Годунов и Пеньков, 2019), и т. д.). Несмотря на расхождения во взглядах, большинство авторов признают первостепенную роль личностных ценностей в организации жизни и деятельности человека - наличие у каждого человека потребности в ценностях, которые и направляют его поступки и управляют чувствами (Фромм, 2018; Франкл, 1990).

Отечественные и зарубежные исследователи (Утюганов, Яницкий и Серый, 2019; Алексеева, 1984; Ермак, 2016; Барадакова, 2017; Волынец, 2017; Зубова и Кириенко, 2018; Калугин, 2017; Колесов, Смолонская и Смолонский, 2017; Лифшиц, 2019; Лобза, Конончук и Эгамбердиева, 2017; Бутакова и Вязигина, 2017; Damasio \& Koller, 2015; Datu, 2016; Donina, Salikhova, Aryabkina, Chernova, \& Kovardakova, 2019; Knyazeva et al., 2019; Litvinova \& Kolomoichuk, 2016; Park \& Baumeister, 2017; Sun, Fan, Sun, Jiang, \& Wang, 2019; и др.) продолжают изучать ценности, входящие в структуру личности. Исследователи высказывают позицию о связи ценностей и потребностей, где потребность выступает инициатором формирования ценности, и, в то же время, на основе ценностей формируется потребность. Стремление человека к смыслу и поиск смысла жизни является одной из основных потребностей человека. В различных науках - психологии, философии, лингвистике, культурологии - убедительно отражен тот факт, что смыслы являются определяющими детерминантами регуляции деятельности личности, и смысл, личностный смысл, жизненные смыслы являются основной инстанцией, подчиняющей себе все другие жизненные проявления личности. Смыслы рассматриваются как субъективное отражение отношения индивида к миру, к объектам, ради которых он развивает свою деятельность. Смыслы выступают как базовая потребность человека. Наличие смысла определяет дальнейшее действие человека, в том числе на принятие или непринятие себя, на выстраивание взаимоотношений с людьми в разных социальных группах. Одним из значимых аспектов для человека является его ближайшее окружение, семья. Понимание смысла и ценности семьи на современном этапе развития общества указывает на сложность и неоднозначность этой темы. Наблюдаются изменения понимания семьи и ее ценности для человека в современном обществе. Сейчас существует много различных видов семьи и семейных отношений, что указывает на изменения в ценностно-смысловой сфере современного человека.

В качестве предположения в нашем исследовании выдвинута идея о том, что ценности и жизненные смыслы женщин и мужчин с изменением их статуса будут изменяться.

\section{Методы}

В исследовании использовались теоретические методы (сравнительный анализ идей и концепций, обобщение теоретических положений) и эмпирические методы (тестирование). В качестве диагностического инструментария были использованы: «Методика исследования системы жизненных смыслов» (Котляков, 2003); «Ценностный опросник Шварца» (Карандашев, 2004; Schwartz et al., 2012), «Опросник самоотношения» В. В. Столина и С. Р. Пантилеева (Глуханюк и Щипанова, 2013).

Методы математической обработки эмпирических данных включали описательную статистику (выявление основных характеристик распределения), U-критерий Манна -Уитни. 
КАРА Ж. Ю., КРУТЕЛЕВА Л. Ю.

ОСОБЕННОСТИ СМЫСЛОЖИЗНЕННЫХ И ЦЕННОСТНЫХ ОРИЕНТАЦИЙ МОЛОДЕЖИ...

Российский психологический жУРнАл, 2019, Т. 16, № 4, 34-41. doi: 10.21702/rpj.2019.4.3

ОБЩАЯ ПСИХОЛОГИЯ, ПСИХОЛОГИЯ ЛИЧНОСТИ, ИСТОРИЯ ПСИХОЛОГИИ

\section{Выборка}

В исследовании приняли участие 61 человек в возрасте 18-35 лет, которые были разделены на 2 группы. В группу 1 вошли 13 женщин и 18 мужчин, находящихся в браке, в группу 2 14 женщин и 16 мужчин, находящихся в поиске партнера.

\section{Результаты и их обсуждение}

В исследовании изучались жизненные смыслы, ценности молодых женщин и мужчин, находящихся в браке и находящихся в поиске партнера, на фоне изменений в обществе, социуме, технологиях, которые неизбежно отразятся на психологических особенностях человека. Применяя методику «Исследования системы жизненных смыслов» (В. Ю. Котляков) мы выявляли степень значимости жизненных смыслов у женщин и мужчин, находящихся в браке и находящихся в поиске партнера, методом описательной статистки. Важно отметить, что в группе лиц у женщин и мужчин, находящихся в поиске партнера, на доминирующих позициях находятся «экзистенциальные», «гедонистические», «самореализация», «семейные», «коммуникативные» жизненные смыслы: ценность жизни как таковой, желание получать от нее удовольствие, самореализовываться, а также выражена потребность в заботе о своей семье, в нахождении своего предназначения, в свободе выбора, в ценности жизни.

Отметим факт, что параметр «семейные смыслы» выражен по-разному у женщин и мужчин, как в группе находящихся в поиске партнера, так и в группе находящихся в браке. Для мужчин по всей выборке в обеих группах «семейные» смыслы одинаково высоко значимы. В то же время в группе женщин, находящихся в поиске партнера, семейные смыслы не имеют большого значения, а в группе женщин, находящихся в браке, они имеют первостепенное значение, и это указывает на существенные изменения, происходящие в жизни женщины. Наблюдается изменение значимости статусных смыслов у мужчин: т.е. для мужчин, находящихся в поиске партнера, «статусные» смыслы по значимости стоят на последнем месте, в то время как после вступления в брак значимость смысла параметра «статус» заметно возрастает, перемещаясь на третье место. Для женщин и мужчин, находящихся в браке, заметно снижается значимость смыслов «самореализация», однако «коммуникативные» смыслы, наоборот, приобретают более весомое значение.

Проверка значимости различий между двумя выборками - находящихся в поиске и находящихся в браке - показала статистически значимые отличия по шкале «самореализация» $\left(U_{\text {эмп }} 287\right.$ при $\left.p \leq 0,01\right)$ : это указывает на то, что при смене социального статуса значимость собственных достижений сдвигается по шкале актуальности на более низкие позиции.

Далее мы изучили ценности данных групп с помощью методики «Ценностный опросник» (Ш. Шварц). Статистически значимые различия по U-критерию Манна - Уитни для данных групп обнаружены по таким шкалам, как «стимуляция» $\left(U_{\text {эмп }}=310,5\right.$ при $\left.p=0,025\right)$ и «гедонизм» $\left(U_{\text {эмп }}=253,5\right.$ при $\left.p=0,02\right)$. На качественном уровне состав значимых ценностей имеет следующую структуру: так, ценности стимуляции выступают как потребность в получении и переживании различных жизненных ситуаций, поддержание активности, насыщаемости деятельностью, получение новизны в разных областях деятельности; в то же время большое значение и влияние оказывает приобретенный социальный опыт, отражающийся на индивидуальных особенностях человека. Другой тип ценностей - гедонистические ценности - в основе содержат мотивационную цель, направленную на получение удовольствия от жизни, наслаждение разнообразием эмоций, ощущений, и это характерно для молодежи в современных реалиях общественной жизни. 
КАРА Ж. Ю., КРУТЕЛЕВА Л. Ю.

ОСОБЕННОСТИ СМЫСЛОЖИЗНЕННЫХ И ЦЕННОСТНЫХ ОРИЕНТАЦИЙ МОЛОДЕЖИ...

Российский психологический жУРнАл, 2019, Т. 16, № 4, 34-41. doi: 10.21702/rpj.2019.4.3

ОБЩАЯ ПСИХОЛОГИЯ, ПСИХОЛОГИЯ ЛИЧНОСТИ, ИСТОРИЯ ПСИХОЛОГИИ

Отметим для группы находящихся в поиске партнера такие выраженные ценности, как «достижения», «самостоятельность», «комфортность», проявляющиеся в достижении личных успехов, значимости на социальной лестнице, приобретении профессиональных компетенций. Демонстрация социальной компетентности (что и составляет содержание этой ценности) в условиях преобладающих культурных стандартов влечет за собой социальное одобрение. Так как это группа молодых людей, то им свойственны желание и стремление проявлять личную самостоятельность и принимать ответственность на себя, чувствовать себя полноценным человеком. На этот возрастной период приходится социальное становление человека и, как следствие, сдерживание и контролирование своих негативных эмоциональных проявлений, вырабатывание самодисциплины, вежливого общения с людьми разных статусов и т. д.

Отметим для группы находящихся в браке такие выраженные ценности, как «безопасность», «достижения», «гедонизм», проявляющиеся в стабильности, гармонии во взаимоотношениях, в стремлении выстраивать свое окружение в более консервативных условиях для понимания и предположения возможных действий и реакций от своего окружения, что предполагает безопасность для себя лично и для собственной семьи, сохранение здоровья, ощущение принадлежности к определенному статусу в обществе. Личные достижения рассматриваются с ракурса имеющихся компетенций и положительной реакции со стороны общества, одобрения и принятия; принимаются культурно-национальные стандарты. Молодые люди, находящиеся в браке, понимают и оценивают удовольствие и наслаждение жизнью в ракурсе своего ближайшего окружения.

Далее мы изучили с помощью поиска корреляционных связей, какие взаимосвязи возможны в нашей выборке респондентов для общей картины понимания молодых людей. С помощью корреляционного анализа Спирмена мы выявили, что существует достоверная взаимосвязь между альтруистическими смыслами и такими ценностями, как конформность, традиции, доброта, универсализм, самостоятельность, гедонизм, власть и безопасность. Выраженность альтруистических смыслов связана с проявлением таких ценностей, как комфортность, традиции, доброта, универсализм, самостоятельность. Чем ниже проявление альтруистических смыслов, тем сильнее будут выражены данные ценности. Наиболее достоверной является обратная связь средней тесноты между альтруистическими смыслами и традициями (при $p<0,05, r=-0,51$ ), и умеренная обратная связь - альтруистические смыслы и доброта (при $p<0,05, r=-0,42$ ). Также умеренная, обратная теснота связи просматривается между альтруистическими смыслами и комфортностью (при $p<0,05, r=-0,34$ ), самостоятельностью (при $p<0,05, r=-0,38$ ), универсализмом (при $p<0,05, r=-0,30)$.

Между экзистенциальными смыслами и добротой существует прямая, умеренная теснота связи при $p<0,05, r=0,41$. При увеличении одного признака будет более выражен и другой. Умеренная, прямая теснота связи просматривается между «гедонистическими смыслами» и такими ценностями, как «доброта» (при $\mathrm{p}<0,05, r=0,31)$ и «комфортность» (при $p<0,05$, $r=0,30)$. Умеренную, обратную тесноту связи мы наблюдаем между смыслами «самореализация» и ценностями «самостоятельность» (при $p<0,05, r=-0,30)$, «власть» (при $p<0,05$, $r=-0,35)$. Между «коммуникативными смыслами» и «традициями» существует умеренная, прямая теснота связи (при $р<0,05, r=0,36$ ), между «семейными смыслами» и «комфортностью», «добротой», «безопасностью» существует обратная взаимозависимость. Наиболее выраженные связями являются «семейные смыслы» и «доброта» (при $р<0,05, r=-0,55)$, 
КАРА Ж. Ю., КРУТЕЛЕВА Л. Ю.

ОСОБЕННОСТИ СМЫСЛОЖИЗНЕННЫХ И ЦЕННОСТНЫХ ОРИЕНТАЦИЙ МОЛОДЕЖИ...

Российский психологический жУРнАл, 2019, Т. 16, № 4, 34-41. doi: 10.21702/rpj.2019.4.3

ОБЩАЯ ПСИХОЛОГИЯ, ПСИХОЛОГИЯ ЛИЧНОСТИ, ИСТОРИЯ ПСИХОЛОГИИ

«семейные смыслы» и «безопасность» (при р < 0,05, r = -0,55). В обоих случаях просматривается обратная, средняя теснота связи. Менее выражена обратная, умеренная связь между «семейными смыслами» и «комфортностью» (при $p<0,05, r=-0,43$ ). Существует умеренная, обратная связь между «гедонизмом» и «когнитивными смыслами» (при $p<0,05, r=-0,38)$.

Как показывают приведенные результаты, в целом преобладание и усиление самостоятельности отодвигают на незначимую позицию заботу о других в ущерб себе (альтруизм) как следствие осмысленного понимания и контроля собственной жизни. Интересно отметить, что чем больше человек придерживается традиции, тем меньше бескорыстия и альтруизма в своих поступках и действиях он проявляет. Возможно, это связано с реалиями современного общества, с четкой задаваемой линией поведения, следованием и выполнением установленных правил и традиций. Свобода выбора, стремление к потребности испытывать и давать любовь, придание смысла самому процессу жизни и направленность на проявления гуманности, отзывчивости характеризуют современных молодых людей, задумывающихся о своей жизни. Молодые люди ориентированы на благополучие, на получение богатой палитры эмоций и ощущений, на стремление быть счастливым. Сохраняется значимость семейных отношений, напрямую связанная с желанием получения безопасности, ориентации на принятые обычаи, продолжение семейного наследия.

\section{Заключение}

Полученные результаты проведенного исследования показывают, что молодежь в современных условиях транзитивного общества выстраивает свою ориентацию на ценности и жизненные смыслы в соответствии с актуальностью существования. Все большее значение приобретают такие ценности и смыслы, как: «безопасность», «достижения», «гедонизм», «самостоятельность», «комфортность», «стимуляция», «самореализация», «экзистенциальные», «коммуникативные», «семейные». Это указывает на формирование иных личностных особенностей молодых людей. На более значимых позициях находятся ценности и жизненные смыслы, направленные на получение удовольствия от жизни, личностное и профессиональное развитие, поддержание культурных стандартов. В то же время, проблемы современного общества подводят молодых людей к другому пониманию и подходу в выстраивании собственной семейной и личной жизни.

Перспективы дальнейшего исследования связаны с расширением выборки и включения параметров информационного пространства.

\section{Литература}

Абакумова, И. В., Годунов, М. В. и Пеньков, Д. В. (2019). Стратегии смыслообразования: переход от дуальности к триалектике. Российский психологический журнал, 16(1), 52-76. doi: 10.21702/rрj.2019.1.3

Алексеева, В. Г. (1984). Ценностные ориентации как фактор жизнедеятельности и развития личности. Психологический журнал, 5(5), 63-71.

Барадакова, Н.В. (2017). Формирование представлений о ченностях частной жизни у студентов вуза (кандидатская диссертация). Южный федеральный университет, Ростов-на-Дону.

Бутакова, Л. О. и Вязигина, С. Ю. (2017). Ценностная составляющая языкового сознания американцев. Вестник Волгоградского государственного университета, 16(2), 99-108. doi: 10.15688/jvolsu2.2017.2.10 
КАРА Ж. Ю., КРУТЕЛЕВА Л. Ю.

ОСОБЕННОСТИ СМЫСЛОЖИЗНЕННЫХ И ЦЕННОСТНЫХ ОРИЕНТАЦИЙ МОЛОДЕЖИ...

Российский психологический жУРнАл, 2019, Т. 16, № 4, 34-41. doi: 10.21702/rpj.2019.4.3

ОБЩАЯ ПСИХОЛОГИЯ, ПСИхОЛОГИЯ лИЧнОстИ, ИСТОРИя ПСИхОЛОГИИ

Волынец, К. В. (2017). Жизнетворчество как условие преодоления экзистенциальной фрустрации. Мир педагогики и психологии, 9(14). Доступ 05 апреля 2019, источник http://scipress.ru/ pedagogy/articles/ zhiznetvorchestvo-kak-uslovie-preodoleniya-ekzistentsialnoj-frustratsii.html

Глуханюк, Н. С. и Щипанова, Д. Е. (2013). Психодиагностика: учебник для студ. учреждений высш. проф. образования. Москва: Академия.

Ермак, В. В. (2016). Ценностные и смысловые особенности личности участников групповой психологической коррекции (кандидатская диссертация). Южный федеральный университет, Ростов-на-Дону.

Зубова, Л. В. и Кириенко, А. А. (2018). К вопросу о взаимосвязи смысложизненных ориентаций и агрессивности подростков. Вестник Оренбургского государственного университета, 2(214), 70-76.

Калугин, А. Ю. (2017). Варианты смысла жизни: эмпирические свидетельства. В А. Л. Журавлёв, В. А. Кольцова (ред.), Фундаментальные и прикладные исследования современной психологии: результаты и перспективы развития (с. 714-720). Москва: Институт психологии РАН.

Кара, Ж. Ю. и Касьянова, Д. В. (2017). Об особенностях трансформации ценностных и жизненных стратегий женщин в период молодости и зрелости. Гуманитарные, социальноэкономические и общественные науки, 8-9, 49-53.

Кара, Ж. Ю. и Крутелёва, Л. Ю. (2012). О соотношении понятий: смысложизненные ориентации, смысложизненные стратегии и смысложизненная концепция личности. Известия Южного федерального университета. Педагогические науки, 3, 111-116.

Карандашев, В. Н. (2004). Методика Шварца для изучения ценностей личности: концепция и методическое руководство. Санкт-Петербург: Речь.

Карпинский, К. В. (2017). Смысложизненный кризис личности: феноменология, механизмы, закономерности (кандидатская диссертация). Москва.

Колесов, В. И., Смолонская, А. Н. и Смолонский, С. И. (2017). Смысл духовного отчуждения человека и его сущность в современном обществе. Мир психологии, 3(91), 113-122.

Котляков, В. Ю. (2003). Методика исследования системы жизненных смыслов. Сибирская психология сегодня: Сборник научных трудов (Вып. 2, с. 18-21). Кемерово: Кузбассвузиздат.

Леонтьев, А. Н. (1971). Потребности, мотивы и эмоции. Москва: Издательство Московского университета.

Леонтьев, Д. А. (2007). Психология смысла. Природа, строение и динамика смысловой реальности (3-е изд., доп.). Москва: Смысл.

Леонтьев, Д. А., Тараненко, О. А. и Калашникова, О. Э. (2017). Специфика осмысленности жизни у различных групп кризисных пациентов. Мир психологии, 3(91), 190-201.

Лифшиц, М.В.(2019). Ценностно-смысловые основания психологического благополучия личности. Научное мнение, 9, 36-41. doi: 10.25807/РВН.22224378.2019.9.36.41

Лобза, О. В., Конончук, И. В. и Эгамбердиева, Е. В. (2017). Ценностные и смысложизненные ориентации современных российских студентов. Международный журнал прикладных и фундаментальных исследований, 11-2, 300-304.

Рубинштейн, С. Л. (2019). Основы общей психологии. Санкт-Петербург: Питер.

Сухарева, Н. Ф. и Филиппова, Н. Ю. (2018). Диагностика смысложизненных ориентаций юношей и девушек. Актуальные проблемы и перспективы развития современной психологии, 1, 141-147.

Узнадзе, Д. Н. (1961). Экспериментальные основы психологии установки. Тбилиси: Изд-во Акад. наук Груз. ССР. 
Утюганов, А. А., Яницкий, М. С. и Серый, А. В. (2019). Нарративные технологии формирования ценностно-смысловых ориентаций личности: психологическое содержание и применение в образовательной практике. Science for Education Today, 9(1), 76-92. doi: 10.15293/2658-6762.1901.05

Франкл, В. (1990). Человек в поисках смысла. Москва: Прогресс.

Фромм, Э. (2018). Человек для себя. Москва: АСТ.

Damasio, B. F., \& Koller, S. H. (2015). Complex experiences of meaning in life: Individual differences among sociodemographic variables, sources of meaning and psychological functioning. Social Indicators Research, 123(1), 161-181. doi: 10.1007/s11205-014-0726-3

Datu, J. A. D. (2016). The synergistic interplay between positive emotions and maximization enhances meaning in life: A study in a collectivist context. Current Psychology, 35, 459-466. doi: 10.1007/s12144-015-9314-1

Donina, O., Salikhova, A., Aryabkina, I., Chernova, Y., \& Kovardakova, M. (2019). Value-semantic filling of the family concept and value orientations of Russian modern young people family life. Amazonia Investiga, 8(22), 58-68. Retrieved from: https://www.amazoniainvestiga.info/ index.php/amazonia/article/view/28

Knyazeva, T. N., Semenova, L. E., Chevachina, A. V., Batuta, M. B., Sidorina, E. V., Vasilyeva, E. N., \& Petyukova, O. N. (2019). Perception of the family as a factor of emotional well-being of adolescents. Modern Journal of Language Teaching Methods, 8(3), 349-355.

Litvinova, O., \& Kolomoichuk, D. (2016). Psychological peculiarities of behaviour strategies in intergenerational family conflicts. Science and Education, 2-3, 138-144. doi: 10.24195/2414-4665-2016-2-3-25

Park, J., \& Baumeister, R. F. (2017). Meaning in life and adjustment to daily stressors. The Journal of Positive Psychology, 12(4), 333-341. doi: 10.1080/17439760.2016.1209542

Schwartz, S. H., Cieciuch, J., Vecchione, M., Davidov, E., Fischer, R., Beierlein, C., ... Konty, M. (2012). Refining the theory of basic individual values. Journal of Personality and Social Psychology, 103(4), 663-688. doi: 10.1037/a0029393

Sun, P., Fan, X., Sun, Y., Jiang, H., \& Wang, L. (2019). Relations between dual filial piety and life satisfaction: The mediating roles of individuating autonomy and relating autonomy. Frontiers in Psychology, 10, 2549. doi: 10.3389/fpsyg.2019.02549 